\title{
The Cognitive Construal of Chinese Imperatives*
}

\author{
Yujuan Feng \\ College of Foreign Language \\ Hunan University \\ Changsha, China \\ School of Foreign Languages \\ Southwest Minzu University \\ Chengdu, China
}

\author{
Zhengguang Liu \\ College of Foreign Language \\ Hunan University \\ Changsha, China
}

\begin{abstract}
Imperatives indicate the speaker's desire to influence future actions, which are generally accomplished by making requests, suggestion, or giving orders. Different form English imperatives, Chinese imperatives don't have fixed syntactic structures or coherent morphology. This article tries to probe into the mechanism of meaning generation in Chinese imperatives from a constructional perspective, in hope of finding a feasible cognitive motivation for the interpretation and comprehension of Chinese imperatives.
\end{abstract}

Keywords-Chinese imperatives; meaning generation; cognitive motivation

\section{INTRODUCTION}

Chinese doesn't have a fixed syntactic construction as that of English imperatives, but a similar grammatical function instead; the recognition of Chinese imperative as an individual and independent sentence pattern has been established only recently. And due to the fact that Chinese linguists have a traditional preference for a functional and analytical perspective rather than formal and structural ones, nearly all the early researches focus on the functional analysis of imperatives as well as modality adverbs and auxiliaries which assist the fulfillment of such functions. Yuan Yulin's "A Research into Modern Chinese Imperative" is well acknowledged as the first comprehensive book on Chinese imperatives, in which he summaries the semantic, syntactic and pragmatic features of this unique Chinese sentence pattern, in addition to an exhaustive analysis into the most frequently used imperative constructions in Chinese [1]. This book also marks the beginning of a new tide of research into this sentence structure from various angles, among which the following two perspectives are worth the attention: a pragmatic study with emphasis on modality represented by Fang Qi and Wang Janjun [2], [3], as well as a study into the different imperative constructions based on Construction Grammar, which is well illustrated by $\mathrm{Lu}$ Jianming [4].

Semantically, an imperative indicates the speaker's desire to influence future actions. This can be accomplished by making requests, giving orders, or making suggestion.

*This paper is supported in part by the "Research Base Project of Sichuan Provincial Education Department" (Number: SCWYH12-28), and in part by "Projects for Basic Scientific Research Funds in Central Colleges and Universities of SMU" (Number: 13SQN40).
Apparently, in Chinese there is no coherent and distinct syntax which characterizes the constructions of imperatives. Moreover, there is no coherent imperative morphology, as well. This paper tries to probe into the mechanism of meaning generation in Chinese imperatives from a constructional perspective in hope of finding a feasible cognitive approach for their interpretation and comprehension.

\section{LITERATURE REVIEW}

The term "imperative" has been used in very different ways, and the views as to what kinds of construction should be designated by this term have varied considerably. While grammarians have most typically used the term imperative to refer to a syntactic category, it has also been used, especially by philosophers, as in description of meaning, to designate the kind of directive meaning associated with commands and requests.

\section{A. English Imperatives}

In English, the imperative is formed by using the bare infinitive form of a verb to give orders, commands, and general instructions. Such sentences are said to be in the imperative mood, which forms a command or request and is often expressed by using special conjugated verb forms. The syntactic structure of English imperatives is often described as a root clause with two crucial identifying characteristics. As demonstrated in (1), the verb appears in its bare form; in (2), an overt subject is optional.

\section{Be quiet! \\ You be quiet!}

Ma Jianzhong's "Ma Shi Wen Tong”, the first Chinese grammar book, is generally acknowledged as the earliest study of the Chinese imperative sentence, in which there was a relatively short space of discussion and no mentioning of the technical term "imperative". Ma described the imperatives as syntactic structures to "ask somebody to do or not to do something", and in the meantime, noticed several related issues, such as default subject, equivalence between “无” (pronounced as "wu" with the rising tone) and “册”(pronounced as "wu” with the falling tone), and etc.[5]. 
The study of imperative sentence in the linguistic circle has almost never been interrupted ever since the coming out of "Ma Shi Wen Tong". However, due to the difference in criteria for judgment, there are a multitude of discrepancies in the qualitative research and categorization of imperative sentences. Therefore, in order to avoid further confusion, the connotation and category of the imperative sentences will be clarified at the very beginning of this paper, so as to establish the foundation for further research.

From the perspective of ideographic function, imperatives can be used to express commands, suggestions, requests, prohibitions, discouragement, begging and so on. This article adopts the classification framework from Yuan Yulin's work, and divides the Chinese imperative sentences into three categories, which is further subdivided into six types: command sentence and injunction sentence, suggestion sentence and dissuasion sentence, request sentence and begging sentence [1].

A command sentence refers to a sentence in which the speaker commands or instructs the hearer to do something, and the negative form of a command sentence is called a prohibition sentence. The tone of a command sentence is tough and unquestionable, which requires the total obedience of the hearer to the instruction of the speaker.

A suggestion sentence refers to a sentence in which the speaker suggests the hearer to do something, and the negative form of a suggestion sentence is called a dissuasion sentence. The suggestion sentence is characterized by indirect and gentle intonation.

A request sentence refers to a sentence in which the speaker asks the hearer to do something, and the negative form of a request sentence is called a begging sentence. The speaker in the request sentence, usually with a humble position, is characterized by a tone of humility.

\section{B. Traditional Research Approaches of Chinese Imperatives}

The traditional research methodology of the Chinese imperative sentence can be divided into the following two schools: mood theory versus function theory.

The mood theory is first put forward by Lv Shuxiang, who contends that the imperative is the mood for controlling actions, and attributes such differences as in command, request, persuasion, and etc., to variations in intonation, while the modern vernacular Chinese resorts to the use of various modal words, as well. Due to the fact that the mood theory is quite consistent with our general sense of language, many scholars have adopted Lv's viewpoint afterwards, whereas there is still no consensus on what the "mood" exactly is in the Chinese linguistic circle. In terms of the criterion for classifying imperative sentences, the traditional mood theory holds that the category and function of the imperative sentences are in correspondence with each other, with the priority on the forms.

Though the function theory has been quoted in earlier research, it is Zhu Dexi who first stated it explicitly in his book "Explanation of Chinese Grammatical Issues". Zhu proposed that "from the functional perspective, Chinese sentence can be divided into five categories: declarative sentence, interrogative sentences, imperative sentence, addressing sentence and exclamatory sentence", and "the function of imperative sentence is to instruct the hearer to do something". Meanwhile, he also admitted that "the relationship between form and function is intricate"[6]. Therefore, the proponents of functionalism generally define imperative sentence as instructions given by the speaker for the hearer to do or not to do something, and hold that, owing to the perplexity and overlapping between form and function, the delivery of imperative function should be deemed as the standard of classification, while the form can only stand as a reference. Yuan Yulin also adopts the functional perspective and divides Chinese imperatives into "core imperative sentence" and "marginal imperative sentence" accordingly [1].

Between the mood theory and functionalism, the latter delineates a wider range, which also includes interrogative sentence with imperative functions, in addition to the traditionally well-accepted ones. More importantly, either one differs from the other only in its emphasis, without completely denying the other.

\section{MeAning Generation Mechanism In ChINESE IMPERATIVES}

The interpretation of Structuralism towards language is mainly based on units of words, which contends that the lexical meaning is the main contributing factor in determining sentence meaning. Shen Jiaxuan points out that the structuralism generally studies the sentence meaning through the bottom-up process, without interpreting the full meaning of a sentence [7]. Valence Grammar is a good case in point to demonstrate the structuralist perspective. It takes the verb as the starting point and holds that each verb has an inherent "valence" ability to decide the quantity and quality of the object. Guided by such a principle, all the grammatical phenomena focus on descriptions of lexical semantics and syntactic rules. The basic assumption of valence grammar is that the eligibility of the whole sentence is determined by all components (verbs as well as related nouns), with the verb being the core element. And thus whether a sentence is eligible or not is, to a large extent, dependent on the meaning of the verb. Though such a top-down approach does make sense, it couldn't explain all the meanings generated by a sentence.

\section{A. Imperatives as Constructions}

As for the large quantities of constructions prevalently existent in nearly all languages, structuralism fails to give a reasonable explanation to both their syntactic and semantic features. While in contrast, Cognitive Linguistics functions as a better substitute. Cognitive linguists believe that the semantic structure of constructions is the real mirror image of human perception and cognition, and there is an innate regularity between the form and the meaning of the sentence, which cannot be deducted naturally from the lexical semantic rules. Goldberg employed the concept of "construction" to explain the form-meaning relationship in 
sentences [8]. As a leading figure in Construction Grammar, Goldberg has been working on this field for many years, and she argues that grammatical constructions, which are larger language units than lexical items, can also affect the meaning of language. Constructions are grammatical facts independent of lexical-semantic rules, which have meanings of their own. In other words, a sentence is not a cluster of sentence elements, but a "gestalt" instead - the whole is larger than the sum of its components. In a construction, the overall meaning of that construction cannot be necessarily derived from the addition of each component meaning. Though the meaning of each component has a great influence on the formation of the overall meaning of a construction, the overall meaning, in turn, also constrains the individual meaning of each component.

Compared with traditional linguistic theory, constructional grammar provides a more feasible and plausible explanation, together with a new perspective for linguistic research. Goldberg holds that there are four kinds of relationship between constructional meaning and lexical meaning: elaborations, force-dynamic relation, preconditions, and co-occurring activity [9]. And the meaning of a sentence comes from the interaction of constructional meaning with lexical meaning. However, the constructional grammar, still in its practice stage, does not offer a concise and predictable criterion for verb admittance into a certain construction.

As to the relationship between constructional meaning and lexical meaning discussed above, roughly speaking, they are generally represented in two ways - namely, consistency and conflict. When they are in consistency with each other, semantic conformity will be achieved and both of these two meanings will be reinforced. But if the two meanings are in conflict with each other, two distinctive results may arise: in one case, the sentence is conceptually unacceptable; in the other, the constructional meaning takes priority, which forces the lexical meaning to accept the constructional meaning, sets the necessary and sufficient conditions for the lexical meaning to enter the construction, and thus eliminates the conflict. The elimination of the meaning conflict is called "coercion", which is the product of constructional structures. When a word enters a certain construction, other components of the same construction will semantically exert a certain structural pressure on that word, or namely, put certain constraints on it, which may add some potential characteristics to that word and grant it the access to that construction.

\section{B. Conditions for Admittance into Imperative Construction}

The imperative sentence is a very common construction and its prototypical meaning is to instruct others to do or not to do something. Generally speaking, an imperative construction needs an action verb to express the dynamic action, but here comes the question: are all dynamic verbs allowed to enter the construction? Or conversely, are all the static verbs not allowed to enter an imperative construction? The answer is definitely negative. Yuan Yulin makes a thorough and penetrating analysis into the restrictions on choices in Chinese imperative constructions from three dimensions of syntax, semantics and pragmatics respectively, and divides the verbs into three categories: human and nonhuman verbs, controllable and non-controllable verbs, volitional and non non-volitional verbs, which are identified as $\mathrm{V}$ [+human] vs. V [-human], V [+controllable] vs. V [controllable], V [+volitional] vs. V [-volitional] [1].

As stipulated by Yuan, the human verbs can enter the imperative constructions while the non-human verbs cannot. The reason is that the constructional meaning of the imperative requires that the subject of the sentence is the second or the first person pronoun; therefore, the predicate verb must be $\mathrm{V}$ [+human]. But not all the human verbs can enter the imperatives: $\mathrm{V}$ [+controllable] can enter the imperative constructions while $\mathrm{V}$ [-controllable] cannot. The reason is that the constructional meaning of the imperative sentence requires the hearer to do or not to do something, so the verb must be $\mathrm{V}$ [+controllable]. Look at the following examples:

$$
\text { 把书拿走! }
$$

“拿”, which means "take” in (3), is a controllable verb while “姓”, which means "have a Chinese character as one's family name" in (4), is a non-controllable verb. As illustrated above, non-controllable verb indicates that the actor cannot do something or cannot avoid doing something voluntarily. Since V [+controllable] can enter the imperative constructions while V [-controllable] cannot, (4) is not an acceptable structure due to the fact that “姓” doesn't satisfy the conditions for admittance into that imperative construction.

Imperative construction has two forms: affirmative form and negative form. While some controllable verbs can enter both the affirmative and negative constructions, others can only enter the negative but not the affirmative ones. Look at the following examples:

$$
\text { *误事! }
$$

The constructional meaning of negative imperatives is to request the hearer not to do something consciously, or to remind the hearer that something shouldn't happen, which doesn't necessarily demand the hearer's volition. Therefore, verbs can be $\mathrm{V}$ [+volitional] as well as V [-volitional] in negative imperative constructions. In contrast, positive imperative constructions express the speaker's request for the hearer to do something consciously, so the predicate verb must be V [+volitional]. That's the reason why “误事”, which means "procrastinate", is acceptable in such negative imperative constructions as (6) but a total nonsense in a positive imperative construction, just like (5).

\section{Cognitive Motivation OF Metonymy IN IMPERATIVES}

There always exists an "interaction" between constructional meaning and lexical meaning, for a construction is a Gestalt, and every instance entering a construction instantiates the overall meaning of that 
construction. It is accepted that the interaction between constructional meaning and lexical meaning is a kind of coercion, or even a metonymic transfer, which contains a derivation and extension of basic category.

Both conceptual metaphor and metonymy are basic cognitive modals for human beings, which are also the cognitive motivation for the derivation and extension of lexical meanings. And metonymy can, to a large extent, exert an even greater influence on our thinking and behavior than metaphor [10]. Therefore, metonymy plays an important role in the interactive process between constructional meaning and lexical meaning, and can offer a more rational explanation of sentence meaning.

As is known to all, the cause-result relationship is very common in the real world, which affects people's cognition towards the objective world. There is a metonymic relation between the cause and result, in which the cause can substitute the result and vice versa. Since this article focuses on analyzing the rule of semantic generation of imperative constructions through the construction grammar, in the following part, we will start from the cognitive function of two conceptual metonymies - EFFECT FOR CAUSE and RESULT FOR ACTION, and try to analyze how to use a top-down approach to eliminate the conflict between constructional meaning and lexical meaning through coercion. Now look at the following two examples:

$$
\text { 别紧张! }
$$

It is clearly seen that (7) and (8) are qualified Chinese imperative constructions and the predicates in both of them are adjectives. But they differ from each other in metonymic mechanism. In (7), “紧张”, which means "nervous”, stands for the effect and can evoke or presuppose the cause for this effect, so the metonymy EFFECT FOR CAUSE takes place as the cognitive motivation behind. While in (8), the metonymic mechanism changes to RESULT FOR ACTION, in which “文明”, equal to “civilized”, is the result of an action. Through the metonymic mapping, static words like adjectives are granted admittance into the imperative constructions successfully.

\section{CONCLUSION}

With imperative sentences set as the research target, this article reviews and compares the traditional research of Chinese imperative sentences, discusses the relationships between constructional meaning and lexical meaning, and analyzes the selection and constraints of constructional meaning on lexical meaning from the perspective of construction grammar. Taking the conceptual metonymy EFFECT FOR CAUSE and RESULT FOR ACTION as examples, this article further analyzes the cognitive motivation of metonymy in Chinese imperative constructions. Conceptual metonymy plays an important role in the formation and understanding of imperative constructions, for the cognitive process of coercion is realized through metonymy. Specifically, when the constructional meaning and lexical meaning clash with each other, the semantic coercion will be established. But when the metonymy is not established successfully within a construction, the pragmatic abnormality will arise. This article tries to probe into the constructional coercion in Chinese imperatives from the perspective of conceptual metonymy, in the hope of providing a theoretically and practically helpful attempt into the metonymic motivation, which is also a part of the author's doctoral thesis. But due to the fact that the syntactic research of metonymy in construction grammar is still in its infancy stage, the research is far from exhaustive, and will hopefully be accomplished in the next stage of the author's research.

\section{REFERENCES}

[1] Yulin, Yuan. A Research into Modern Chinese Imperative. Beijing Peking University Press, 1993.

[2] Qi, Fang. Pragmatic Study into the Modern Chinese Imperative. Linguistic Research, 1999(4), pp. 14-18.

[3] Jianjun, Wang. Change of Pragmatic Function and Semantic Structure of Chinese Imperative - A Case Study of Zhe. Article presented at the 13th Modern Chinese Research Seminar, 2008.

[4] Jianming, Lu. The Construction Grammar and the Study of Chinese Chinese Language, 2004 (5), pp. 412-416.

[5] Jianzhong, Ma. Ma Shi Wen Tong. Beijing: The Commercial Press, 1983, pp.333.

[6] Dexi, Zhu. Explanation of Chinese Grammatical Issues. Beijing: The Commercial Press, 1982, pp. 23-24.

[7] Jiaxuan, Shen. Valency and Sentence Patterns. Chinese Language, 2000(4), pp. 291-297.

[8] Goldberg, A. Constructions: A Construction Grammar Approach to Argument Structure. Chicago: The University of Chicago Press , 1995.

[9] Goldberg, A. The relationships between verbs and constructions. In M. Verspoor, K. L ee. \& E. Sweetser(eds.). Lexical and Syntactical Constructions and the Construction of Meaning. Philadelphia / Amsterdam: John Benjamins Publishing Company, 1997, pp. 383-98.

[10] Panther, Klaus-Uwe \& Linda L. Thornburg. Coercion and Metonymy: The Interaction of Constructional and Lexical Meaning. Cognitive Perspectives on Language. In Barbara Lewandowska-Tomaszczyk (eds.). Frankfurt am Main: Peter Lang GmbH, 1999. 